\title{
Diet, satiety and obesity treatment
}

The prevention and treatment of obesity have become a matter of major preoccupation in a context where public health approaches attempting to deal with this issue have not been very successful so far. For instance, the traditional approach regarding the use of diet to promote weight loss in obese individuals has been strictly based on the first law of thermodynamics. Indeed, in the medical management of obesity, it has been a regular practice to prescribe low-and very-low-energy diets to promote an energy deficit and to produce significant weight loss. Over the last decade, it has become obvious that this approach is associated with little long-term success and the focus of a successful weight loss programme has been progressively moved towards the use of regimens favouring a decrease in energy intake while preserving the highest level of satiety as possible. In this regard, the impact of reducing the fat content of the diet has probably represented the first step among dietary manipulations associated with a spontaneous decrease in energy intake and body weight without an a priori intervention to reduce energy intake (Lissner et al. 1987; Tremblay et al. 1989). This type of approach has indeed been shown to favour satiety while reducing spontaneous energy intake (Lawton et al. 1993). More recently, the effects of increasing protein intake as well as the intake of carbohydrate containing-foods with a low glycaemic index (GI) have also been examined and discussed (Holt et al. 1992; Skov et al. 1999). For the clinician, these findings are important since they offer prescription elements that have the potential to maximize the impact of a low-fat diet on the reduction of ad libitum energy intake. This preoccupation constituted the main object of our study (Dumesnil et al. 2001) recently reported in the British Journal of Nutrition and which was aimed at measuring the short-term effects of a low-GI-low-fathigh-protein diet on ad libitum energy intake and the atherogenic metabolic risk profile in a sample of obese men. Following the publication of our paper, Dr Thomas Wolever sent to the Editor of the British Journal of Nutrition an article (Wolever, 2002) in which he addressed specific criticisms regarding the measurement of GI in our study. We thank Dr Wolever for his interest in our study and for his 'lecture' on the glycaemic index concept and we would like to make the following points.

\section{Diet and satiety}

As indicated earlier, the systematic focus for decades of health professionals and public health agencies on hypoenergetic diets is emerging today as a mistake with minimal long-term effects on body weight, a failure poorly recognized by health professionals. In this case, the main challenge for the nutritionist is to design a regimen that represents a healthy diet, which would simultaneously promote satiety and a decrease in ad libitum energy intake. In other words, this objective implies for the patient that his or her therapist must have been sufficiently creative and competent to favour weight loss while preserving satiety, which is such an essential and pleasant feature of the diet. In this regard, the study that we recently published in the British Journal of Nutrition (Dumesnil et al. 2001) can be considered as a success, at least on a short-term basis. Indeed, the results demonstrated that the low-GIlow-fat-high-protein diet (regimen two) was associated with a spontaneous decrease in energy intake of $25 \%$ compared with the intake observed when the subjects had free access to foods with a composition respecting the guidelines of the American Heart Association (AHA, Krauss et al. 1996). Considering the fact that the AHA diet also represents a regimen favouring satiety with a reduced energy intake compared with a high-fat diet, the experimental diet tested in our study represents a potentially significant gain for the clinician compared with what has been reported so far, if these results are validated with long-term studies.

Even if our results are rather convincing in terms of the ability of regimen two to promote a decreased energy intake while preserving satiety, we are aware that considerable efforts will have to be devoted to changing the traditional paradigm of health professionals and scientists regarding what may constitute the optimal dietary approach for weight-reducing programme. To this effect, the fact that an established scientist like Dr Wolever totally ignores this contribution also indicates that it will take some time before a decrease in energy intake is perceived as a consequence of a healthy diet rather than an a priori dietetic necessity.

\section{Measurement of the glycaemic index of foods}

The main focus of Dr Wolever's article (Wolever, 2002) on our paper (Dumesnil et al. 2001) pertains to the specific measurement of GI for various food items of our menus. Indeed, Dr Wolever takes great pains in emphasizing the potential lack of accuracy of GI measurements for food items like bread, fruits, jam, etc. We do not disagree with the limitation associated with the lack of directly measured GI results regarding some specific items in our study. In fact, the problem is not that different from the situation when we have to derive the nutrient intake of a subject by assuming that his or her reported foods have the same nutrient value as that of foods listed in tables. However, while acknowledging this limitation, we also feel that Dr Wolever devoted so much attention to this issue that he has lost perspective on the contribution of our study. As far as we know, GI is an indicator of the glycaemic response to a standardized portion of carbohydrate from a specific food and from a clinical standpoint, there is no reason why this concept should not be ultimately extended to the whole regimen. The latter point represents what has been up to now the main weakness of studies 
focusing on the GI value of each food item taken at any given time. Again, we perceive that our study offers a significant contribution to this specific area of research because, to our knowledge, our study is probably the first one documenting variations in GI of the whole regimen measured under free-living conditions when subjects are either eating ad libitum or tested under well-controlled isoenergetic conditions. In this regard, the fact that Dr Wolever did not refer to our Fig. 3, which clearly demonstrates that the area under the glucose curve remained significantly lower when our low-GI-low-fat-high-protein diet was served at the same energetic level as under the AHA regimen is perceived as a disappointing omission on his part. The definition of the GI concept is not our most important concern; we care more for the epidemic proportion reached by obesity and by the need to provide patients with simple and efficient nutritional guidance.

\section{Glycaemic index and satiety}

Dr Wolever also emphasized the fact that it is not relevant to estimate the GI values of foods like cheese, lettuce and yellow waxed beans because their carbohydrate content is too low to have an impact on the control of glycaemia. This type of argument may be justified if we deal with the diet prescription prepared for a diabetic patient in order to produce an optimal glycaemic control. However, it is much more difficult to consider the measurement of GI of these foods as trivial in the context of optimal appetite control of obese individuals. Even if Dr Wolever has not contributed himself to the literature on the relationship of GI to satiety, he is probably aware that there is published evidence emphasizing the potential benefit of consuming low-GI foods on satiety. However, if this effect really exists, the mechanism by which low-GI foods promote satiety is unknown. One possible explanation for satiety could be that these foods could prevent episodes of mild hypoglycaemia after a glycaemic peak. Again, if this was found to be true, it might appear relevant not only to measure GI of high-carbohydrate foods but also those with low carbohydrate content.

One of the main points made by Dr Wolever was that the conclusions of our paper related to GI were unjustified because the study fails to demonstrate that the GI of our experimental diet was lower than that of our control diet. We disagree with this conclusion and we believe rather that our study provides a good example of the impact of a multiple-food GI manipulation on the glycaemic response to the whole regimen, particularly under isoenergetic conditions. Moreover, the favourable impact of the low-GIlow-fat-high-protein diet on reducing daily energy intake and on improving the metabolic risk profile offers interesting perspectives for preventive and therapeutic interventions in obese individuals. We certainly recognize the limitations of our short-term study and indeed the fact that we do not have an item-by-item measurement of the GI values of the foods consumed by our subjects. However, results shown in Fig. 3 indicate that there was indeed a lower daytime glycaemic response to regimen two. In addition, these promising findings were received with interest and enthusiasm by colleagues from all over the world, preoccupied by the development of simple nutritional solutions for our obese patients with documented efficacy.

$$
\begin{array}{r}
\text { Angelo Tremblay } \\
\text { Division of Kinesiology } \\
\text { Faculty of Medicine } \\
\text { Laval University } \\
\text { Québec } \\
\text { Canada } \\
\text { Jean G. Dumesnil } \\
\text { Québec Heart Institute } \\
\text { Laval Hospital Research Center } \\
\text { Québec } \\
\text { Canada } \\
\\
\text { Jean-Pierre Després } \\
\text { Québec Heart Institute } \\
\text { Laval Hospital Research Center } \\
\text { Québec } \\
\text { Canada }
\end{array}
$$

\section{References}

Dumesnil JG, Turgeon J, Tremblay A, Poirier P, Gibert M, Gagnon L, St-Pierre S, Garneau C, Lemieux I, Pascot A, Bergeron J \& Després J-P (2001) Effect of a low-glycaemic index-low-fat-high protein diet on the atherogenic metabolic risk profile of abdominally obese men. British Journal of Nutrition 86, 557-568.

Holt S, Brand J, Soveny C \& Hansky J (1992) Relationship of satiety to postprandial glycaemic, insulin and cholecystokinin responses. Appetite 18, 129-141.

Krauss RM, Deckelbaum RJ, Ernst N, Fisher E, Howard BV, Knopp RH, Kotchen T, Lichtenstein AH, McGill HC, Pearson TA, Prewitt TE, Stone NJ, Horn LU \& Weinberg R (1996) Dietary guidelines for healthy American adults. A statement for health professionals from the Nutrition Committee, American Heart Association Circulation 94, 1795-1800.

Lawton CL, Burley VJ, Wales JK \& Blundell JE (1993) Dietary fat and appetite control in obese subjects: weak effects on satiation and satiety. International Journal of Obesity 17, 409-416.

Lissner L, Levitsky DA, Strupp BJ, Kalkwarf HJ \& Roe DA (1987) Dietary fat and the regulation of energy intake in human subjects. American Journal of Clinical Nutrition 46, $886-892$.

Skov AR, Toubro S, Ronn B, Holm L \& Astrup A (1999) Randomized trial on protein vs carbohydrate in ad libitum fat reduced diet for the treatment of obesity. International Journal of Obesity 23, 528-536.

Tremblay A, Plourde G, Despres JP \& Bouchard C (1989) Impact of dietary fat content and fat oxidation on energy intake in humans. American Journal of Clinical Nutrition 49, 799-805.

Wolever TMS (2002) Low carbohydrate does not mean low glycaemic index! British Journal of Nutrition 88, 211-212. 